\title{
APLIKASI PENJUALAN DAN DELIVERY ORDER PADA CAFÉ GIOVA'S SENTUL BERBASIS JAVA
}

\author{
Jihan Septi Rahayu' ${ }^{1}$ Ika Mei Lina² \\ 1,2Informatika, Fakultas Teknik dan Ilmu Komputer, Universitas Indraprasta PGRI \\ Jalan Raya Tengah No 80, Kelurahan Gedong, Pasar Rebo, Jakarta Timur \\ 1.jihansepti.1007@gmail.com, ${ }^{2}$ ikameilina.24@gmail.com
}

\begin{abstract}
ABSTRAK
Penggunaan sistem manual dalam proses bisnis pada Café Giova's menyebabkan hambatan pada pengelolaan data sehingga menimbulkan kurang efektif, efisien, dan tidak tepat waktu dalam pembuatan laporan yang dibutuhkan. Berdasarkan permasalahan tersebut maka tujuan penelitian ini adalah menciptakan aplikasi berbasis desktop Java dengan basis data MySQL sebagai media sistem informasi penjualan dan delivery order yang akan digunakan di café. Adapun dalam merancang dan membuat sistem informasi penjualan dan delivery order pada Café Giova's Sentul dengan menggunakan metode penelitian R\&D (Research and Development) dalam merancang serta melakukan perubahan di dalam sistem yang memiliki beberapa tahapan, yaitu pengumpulan data, analisis, desain sistem, dan lainnya. Penelitian ini menghasilkan aplikasi penjualan dan delivery order berbasis desktop yang mempermudah dalam pengelolaan data dan penyajian informasi penjualan dan delivery order di Café Giova's Sentul dengan efisien, efektif, dan tepat waktu.
\end{abstract}

Kata Kunci: Sistem, Informasi, Penjualan, Desktop, Java.

\begin{abstract}
The use of manual systems in business processes at Café Giova's causes obstacles in data management so that it is less effective, efficient, and not timely in making the required reports. Based on these problems, the purpose of this research is to create a Java desktop-based application with a MYSQL database as a media for sales and delivery order information systems that will be used in cafes. As for designing and creating a sales and delivery order information system at Café Giova's Sentul by using the $R \& D$ (Research and Development) research method in designing and making changes in the system which has several stages, namely data collection, analysis, system design, and others. This research produces a desktop-based sales and delivery order application that makes it easier to manage data and present sales and delivery order information at Café Giova's Sentul efficiently, effectively, and on time.
\end{abstract}

Key Word: System, Information, Sales, Desktop, Java.

\section{PENDAHULUAN}

Pada era globalisasi saat ini, kebutuhan akan informasi yang cepat, tepat, dan akurat sangat penting. Berbagai perusahaan berusaha mengembangkan usahanya dengan melakukan banyak perubahan dengan memanfaatkan teknologi yang canggih seperti komputer sebagai pengganti tenaga kerja manusia, dimana komputer tersebut menunjang perusahaan dalam mengambil keputusan yang didukung oleh komponen penting dari teknologi informasi, yaitu database (basis data). Database merupakan sarana yang berfungsi sebagai tempat penyimpanan data, yang disamping itu juga dapat mengatur sistem penambahan data baru, mengubah, dan menghapus data serta hubungan antar data-data yang disimpan, sehingga Ketika dibutuhkan maka perusahaan akan dengan mudah menggunakan data yang telah terstruktur, cepat, dan akurat.
Café Giova's Sentul merupakan salah satu perusahaan perorangan yang bergerak dibidang food \& beverage yang berlokasi di Sentul, Jawa Barat. Café Giova's ini mengalami kesulitan dan tidak efisien dalam mengelola data-data mengenai data penjualan. Data-data tersebut kurang terstruktur dengan rapih dan dilakukan secara manual, yaitu dengan menggunakan kertas tulis yang mengakibatkan tidak sesuai dengan pencatatan awal dan kertas nota transaksi. Pengelolaan laporan penjualan juga dilakukan dengan manual dengan menggunakan kertas dan hanya menggunakan alat bantu kalkulator sebagai media perhitungan, sehingga terjadi keterlambatan informasi dan kesalahan informasi.

Aplikasi adalah program siap pakai yang dapat digunakan untuk menjalankan perintah- 
perintah dari pengguna aplikasi tersebut dengan tujuan mendapatkan hasil yang lebih akurat sesuai dengan tujuan pembuatan aplikasi tersebut.(Abdurahman, 2014)

Aplikasi adalah alat terapan yang difungsikan secara khusus dan terpadu sesuai kemampuan yang dimilikinya. Sehingga alat ini dapat digunakan untuk pembuatan rancangan yang mudah.(Sutabri, 2012a)

Aplikasi adalah sekelompok atribut yang terdiri dari beberapa form, report yang disusun sedemikian rupa sehingga dapat mengakses data. Aplikasi merupakan program yang berisikan perintahperintah untuk melakukan pengolahan data. (Santoso, 2012)

Penjualan merupakan kegiatan manusia yang bertujuan untuk memuaskan kebutuhan dan keinginan langganan, melalui proses pertukuran yang bertujuan untuk memuaskan kebutuhan dan keinginan langganan, melalui proses pertukaran dan kepada pihak-pihak yang berkepentingan dengan perusahaan (Isnandi \& Wardati, 2014)

Penjualan adalah penerimaan yang diperoleh dari pengiriman barang dagangan atau dari penyelesaian pelayanan dalam bursa sebagai bahan pertimbangan. Pertimbangan ini dapat dalam bentuk tunai peralatan kas atau harta lainnya. Pendapatan dapat diperoleh pada saat penjualan, karena terjadi pertukaran, harga jual dapat ditetapkan dan bebannya diketahui.(Ginting, 2013)

Penjualan adalah konsep lugas yang diantaranya berupa usaha membujuk pelanggan untuk membeli sebuah produk.(Westwood, 2011)

Penjualan adalah transaksi perubahan nilai barang menjadi nilai uang atau nilai piutang dagang. (Sutabri, 2012b)

Delivery Order adalah suatu layanan dalam perusahaan untuk memenuhi kebutuhan konsumen dalam hal pemesanan suatu barang atau layanan jasa. (Leon A. Abdillah., 2021)

Java merupakan bahasa pemrograman berorientasi objek dan bebas platform, dikembangkan oleh SUN Micro system dengan jumlah keunggulan yang memungkinkan Java dijadikan sebagai bahasa pengembang enterprise.(Isnandi \& Wardati, 2014)

Java merupakan bahasa berorientasi objek untuk pengembangan aplikasi mandiri, aplikasi berbasis internet, aplikasi perangkat cerdas yang dapat berkomunikasi lewat internet atau jaringan komunikasi. (Haryanto, 2011)

Java dikembangkan oleh perusahaan Sun Microsystem. Java menurut definisi Sun Microsystem adalah nama untuk sekumpulan teknologi untuk membuat dan menjalankan perangkat lunak pada komputer standalone ataupun pada lingkungan jaringan. Java 2 adalah generasi kedua dari java platform. (Rosa, A.S. dan Shalahudin, 2014)

Oleh karena itu, untuk mendukung sistem informasi penjualan dan delivery order yang efektif perlu dirancang suatu sistem basis data penjualan dan delivery order berbasis desktop yang lebih mudah digunakan, sehingga akan membantu dalam mengolah data - data yang dibutuhkan menjadi lebih akurat, efisien, dan hemat waktu.

Tujuan dari penelitian ini, yaitu untuk merancang dan mengimplementasikan aplikasi sistem informasi penjualan dan delivery order, pendataan pelanggan, pendataan menu, dan pendataan transaksi pada Café Giova's Sentul, serta mengevaluasi sistem informasi yang telah dihasilkan.

\section{METODE PENELITIAN}

Penelitian dilakukan pada Café Giova's Sentul yang beralamat di Jl. Siliwangi No. 3, Cijujung, Kec. Sukaraja, Bogor, Jawa Barat. Penelitian dilakukan selama 6 bulan terhitung mulai bulan Maret 2021 sampai dengan bulan Agustus 2021.

Metode penelitian yang digunakan adalah metode Research and Development (R\&D). Research and Development adalah suatu proses atau langkah - langkah untuk mengembangkan suatu produk baru atau menyempurnakan produk yang telah ada.

Metode Pengumpulan Data

1. Studi kepustakaan, pengumpulan data dan informasi dari kutipan buku - buku, peraturan perundang - undangan, dan 
hasil laporan serta bahan lainnya yang berkaitan dengan penelitian ini.

2. Wawancara

Dengan cara melakukan tanya jawab langsung kepada Pimpinan Café Giova's Sentul, Ibu Trisya. Pertanyaan yang diajukan seputar sistem penjualan yang sedang berjalan pada Café Giova's Sentul.

3. Observasi

Melakukan pengumpulan data dengan mengadakan pengamatan langsung pada Café Giova's Sentul.

\section{HASIL DAN PEMBAHASAN}

Alternatif Penyelesaian Masalah

1. Sistem yang ada di Café Giova's diubah menjadi sistem informasi berbasis Java agar pengolahan data menjadi efektif, efisien, akurat dan mudah dalam melakukan pengolahan administrasi penjualan.

2. Dengan adanya sistem penjualan diharapkan data akan lebih mudah terkomputerisasi dan terstruktur, jika tidak ada kertas menumpuk di pelayanan terlebih dahulu.

3. Dengan aplikasi ini diharapkan memudahkan pencarian data yang lebih efektif dan efisien.

4. Memanfaatkan seluruh sumber daya yang efektif melalui aplikasi dalam pengolahan data dan penyajian laporan yang dibutuhkan.

5. Dengan sistem informasi ini diharapkan memudahkan dalam pembuatan laporan dan penyimpanan hasil laporan tersebut.

6. Dengan adanya sistem delivery order ini membuat pelanggan bisa memesan tanpa harus datang ke tempat.

Aturan bisnis sistem berjalan yang diusulkan dalam sistem informasi penjualan ini adalah sebagai berikut :

1. Proses Pendataan

Pada setiap pelanggan baru, adanya menu baru, karyawan baru yang belum terdaftar harus dilakukan pendataan terlebih dahulu

2. Proses Pemesanan

Pada setiap pelanggan yang memesan menu ke karyawan terlebih dahulu melakukan proses pemesanan.

3. Proses Delivery Order

Pada setiap pelanggan yang melakukan pemesanan via chat atau telepon, karyawan menginput terlebih dahulu pesanan pelanggan, kemudian data ini akan disimpan ke datastore delivery order.

4. Laporan

Laporan bersumber dari datastore. Laporan dicetak untuk diserahkan kepada pemilik café untuk diperiksa dan ditandatangani.

\section{Diagram Alir Data (DAD) Sistem yang Diusulkan}

Berikut DAD sistem yang diusulkan pada sistem informasi penjualan dan delivery order Café Giova's garden Sentul dalam bentuk diagram konteks :

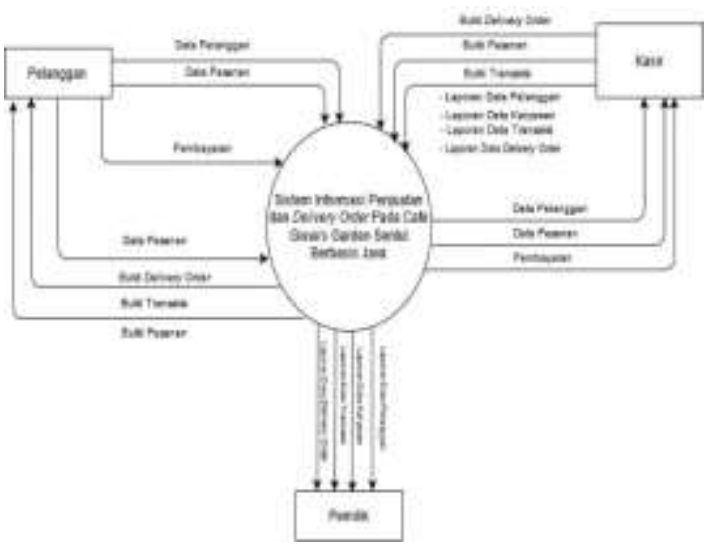

Gambar 1. Diagram Konteks Sistem yang Diusulkan

\section{Entity Relationship Diagram (ERD)}

Berikut ini gambaran sistem yang diusulkan pada sistem informasi penjualan dan delivery order café giova's garden Sentul dalam bentuk ERD :

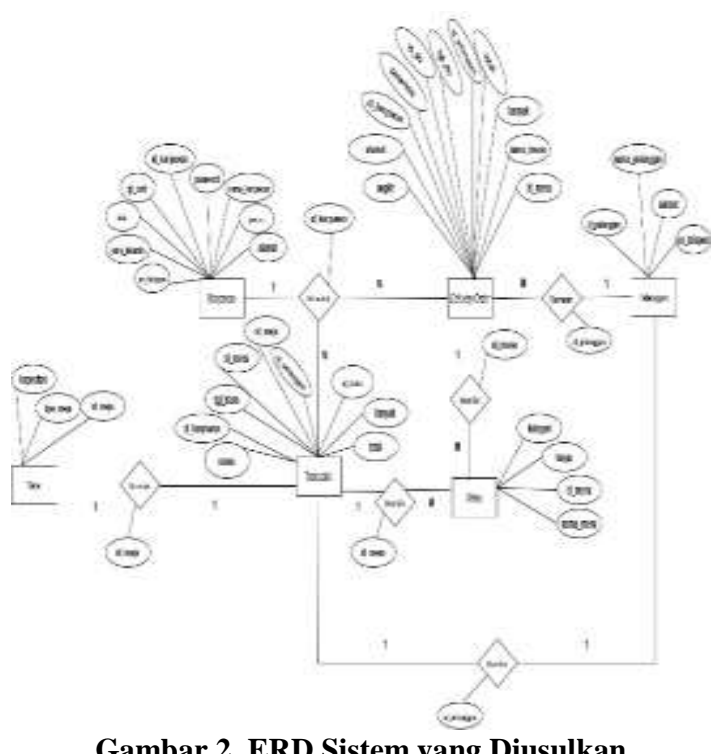

Gambar 2. ERD Sistem yang Diusulkan 


\section{Tampilan Layar, Tampilan Format Masukan, dan Tampilan Keluaran}

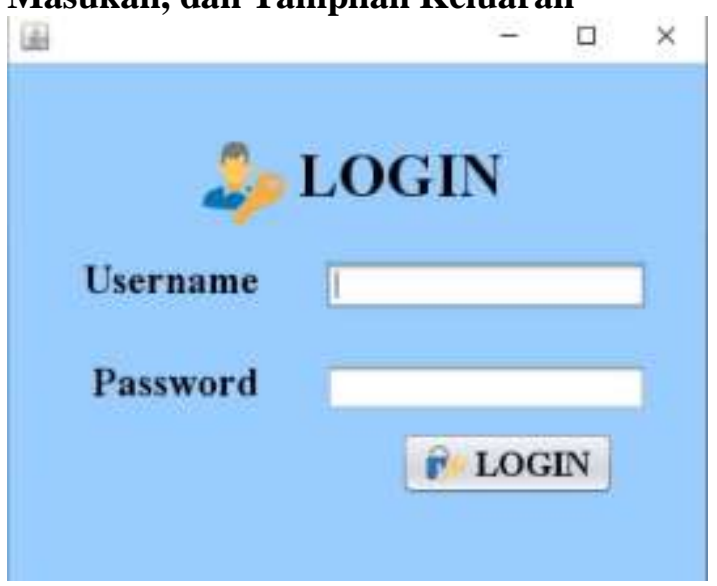

Gambar 3. Tampilan Login

Tampilan login akan muncul ketika program dijalankan, username dan password bersumber dari database karyawan. Menu ini muncul setiap kali program baru dijalankan, yang dapat mengoperasikan aplikasi ini hanya karyawan selaku kasir. Untuk dapat mengoperasikan aplikasi ini kasir harus memasukkan username dan password yang sesuai.

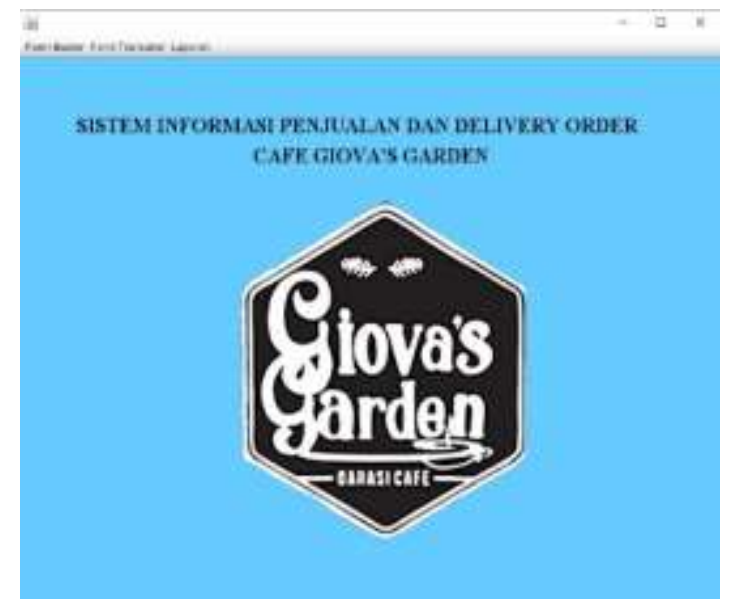

Gambar 4. Tampilan Menu Utama

Pada menu utama terdapat menu form master, form transaksi, dan laporan. Pada form master terdapat sub menu data pelanggan, data karyawan, data menu café, dan data menu meja. Pada form transaksi terdapat sub menu transaksi dan delivery order.

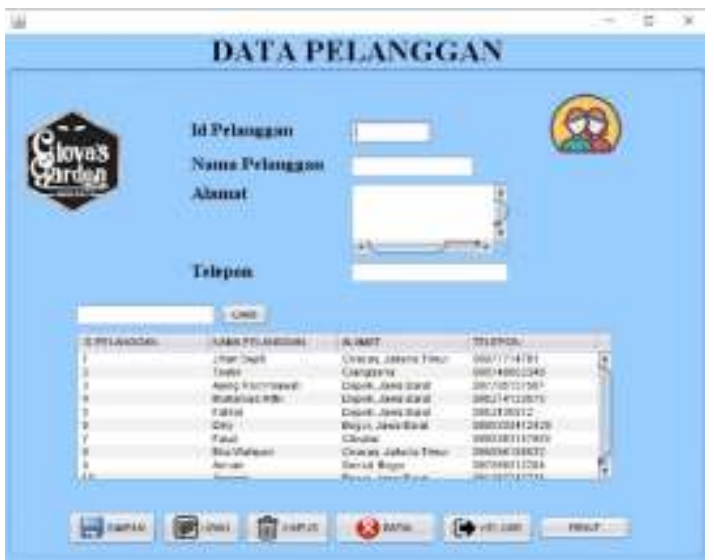

Gambar 5. Tampilan Data Pelanggan

Pada form pelanggan, kasir dapat mendata pelanggan yang akan disimpan ke dalam database sistem. Kasir dapat menambahkan, mengubah, dan menghapus data pelanggan. Form pelanggan ini diisi dengan data pelanggan yang melakukan pemesanan menu.

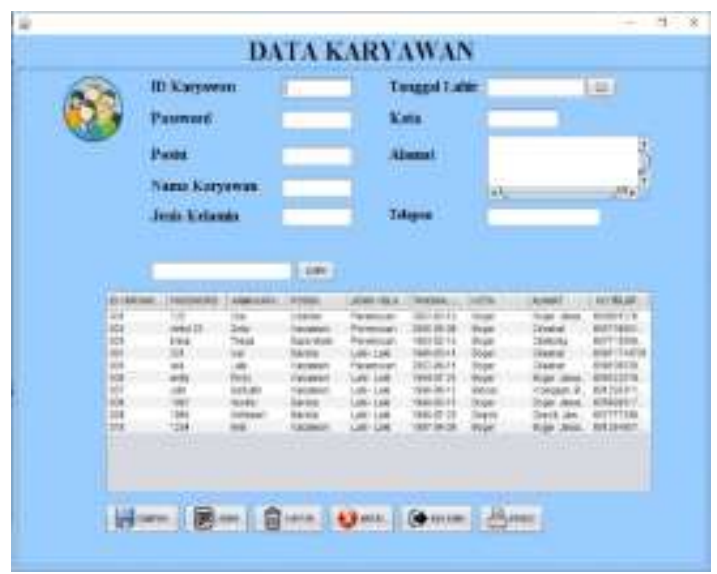

Gambar 6. Tampilan Data Karyawan

Pada form karyawan diisi dengan data keseluruhan karyawan café dan karyawan yang bertugas sebagai admin atau backup kasir. Pada form ini admin/Kasir dapat menyimpan, mengubah, menghapus data karyawan.

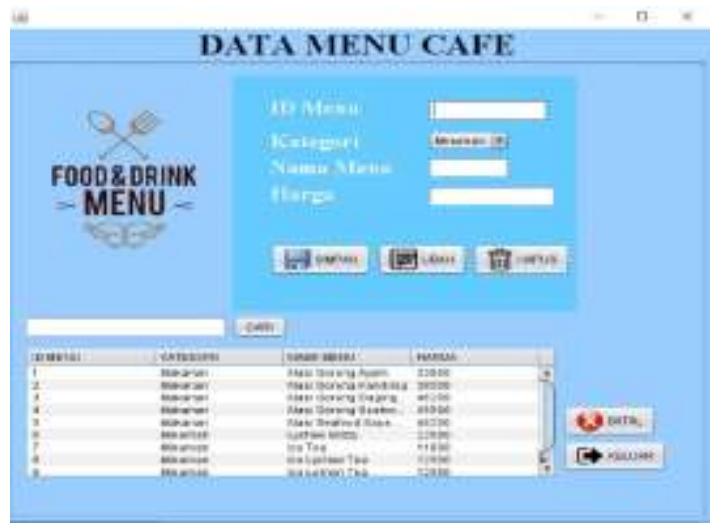

Gambar 7. Tampilan Data Menu Café

1090 | Aplikasi Penjualan dan Delivery Order pada Café Giova’s Garden Sentul Berbasis Java 
Pada form menu café, diisi dengan data menu yang tersedia ataupun menu baru pada café. Pada form ini admin/Kasir dapat menyimpan, mengubah, dan menghapus data menu café.

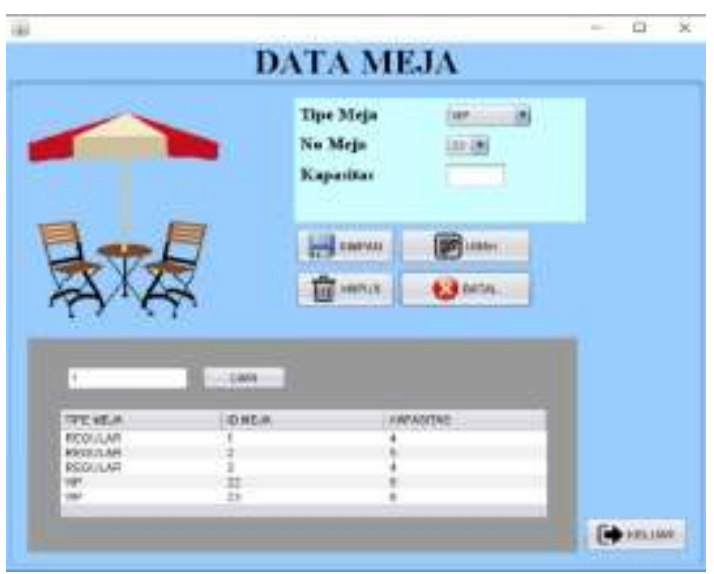

Gambar 8. Tampilan Data Meja

Pada form meja, diisi dengan data meja keseluruhan yang ada pada café. Pada data meja ini bisa mengetahui berapa kapasitas pelanggan dalam satu meja. Pada form ini admin/Kasir dapat menyimpan, mengubah, dan menghapus data meja.

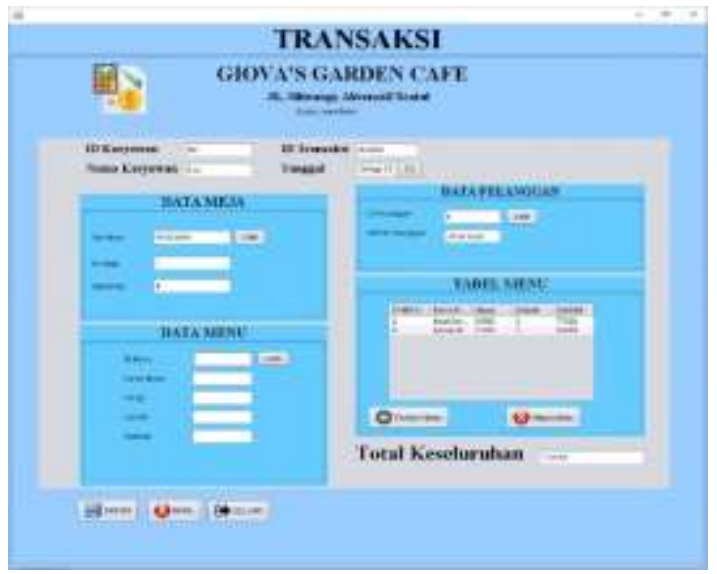

Gambar 9. Tampilan Data Transaksi

Pada form transaksi, diisi dengan data transaksi pesanan pada pelanggan. Kasir dapat menyimpan, menghapus, menambah transaksi pesanan. Setelah disimpan kasir mencetak bukti transaksi berupa struk pembayaran yang kemudian diserahkan kepada pelanggan.

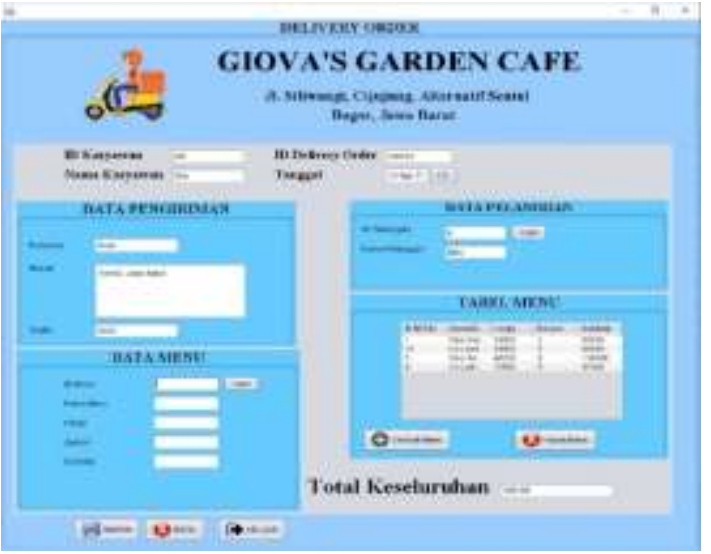

Gambar 10. Tampilan Data Delivery Order

Pada form delivery order, diisi dengan data delivery order pada pelanggan yang memesan melalui via chat tanpa harus datang langsung ke café. Kasir dapat menyimpan, menambahkan pesanan menu, menghapus pesanan menu. Setelah disimpan kasir mencetak bukti delivery order yang kemudian dikirimkan melalui via chat dan diserahkan pada saat pengantaran pesanan.

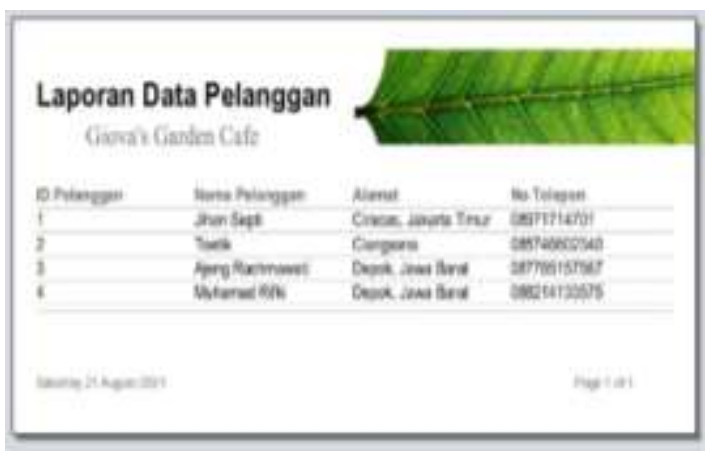

Gambar 11. Tampilan Laporan Pelanggan

Pada laporan pelanggan, merupakan hasil cetak data pelanggan pada form pelanggan yang berisikan data pelanggan yang akan diberikan kepada pimpinan café.

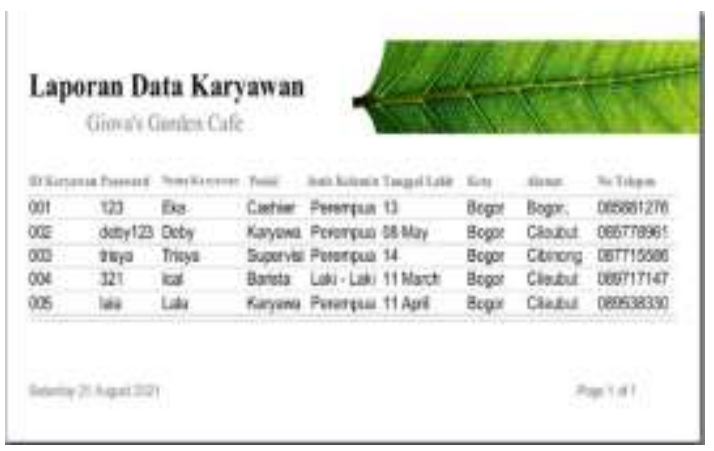

Gambar 12. Tampilan Laporan Karyawan

Pada laporan karyawan, merupakan hasil cetak data karyawan pada form karyawan 
yang berisikan data karyawan yang akan diberikan kepada pimpinan café.

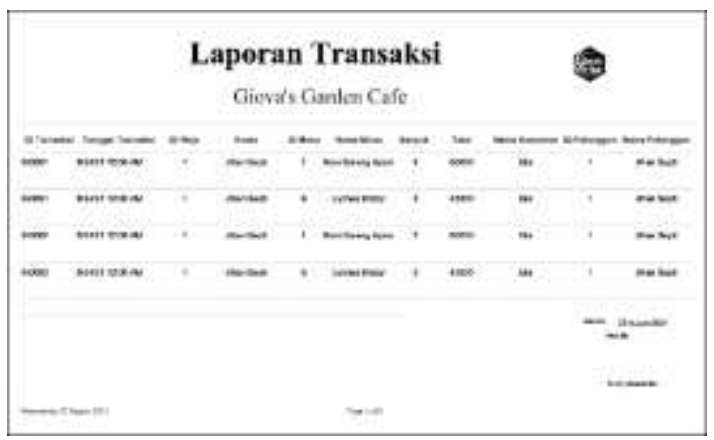

Gambar 13. Tampilan Laporan Transaksi

Pada laporan transaksi, merupakan hasil cetak data transaksi pada form transaksi yang berisikan data transaksi yang akan diberikan kepada pimpinan café.

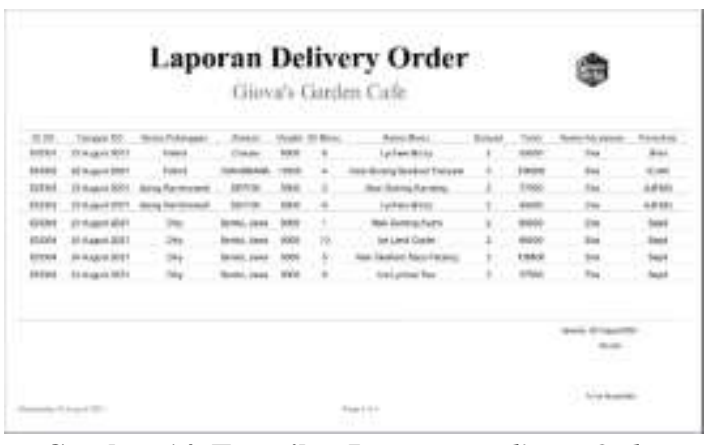

Gambar 14. Tampilan Laporan Delivery Order

Pada laporan delivery order, merupakan hasil cetak data delivery order pada form delivery order yang berisikan data delivery order yang akan diberikan kepada pimpinan café.

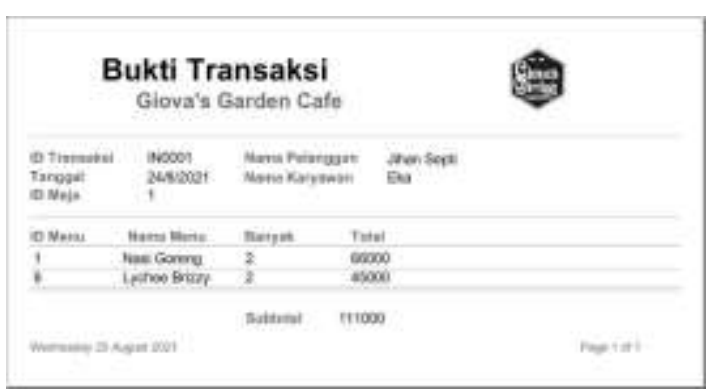

Gambar 15. Tampilan Bukti Transaksi

Pada bukti transaksi, merupakan hasil cetak data transaksi pada form transaksi yang berisikan data transaksi yang diserahkan pada pelanggan pada saat melakukan pembayaran.

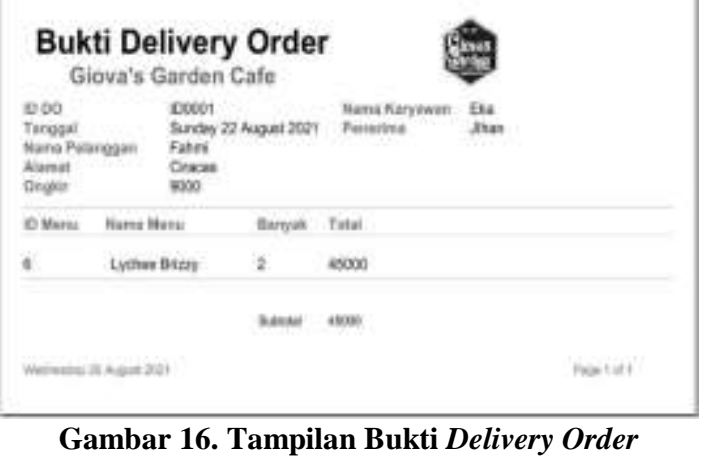

Pada bukti delivery order, merupakan hasil cetak data delivery order pada form delivery order yang berisikan data delivery order yang diserahkan pada pelanggan pada saat pengantaran pesanan.

\section{SIMPULAN DAN SARAN}

Berdasarkan pembahasan yang telah dilakukan, maka dapat diambil simpulan, diantaranya sebagai berikut:

1. Dengan perancangan sistem informasi penjualan dan delivery order pada café menggantikan sistem yang lama, kinerja pegawai saat ini menjadi lebih efektif dan efisien. Pelayan tidak perlu melakukan pendataan dan ketersediaan menu secara manual.

2. Sistem informasi penjualan dan delivery order mempunyai menu login yang hanya bisa diakses oleh kasir dan pemilik untuk masuk kedalam sistem informasi penjualan dan delivery order.

3. Pengembangan sistem informasi penjualan dan delivery order pada café giova's garden dilakukan dengan menggunakan sistem informasi berbasis desktop menggunakan bahasa pemrograman Java dan penyimpanan data pada media database MySQL. Dengan adanya aplikasi yang dibuat ini dapat memperbaharui dalam pendataan pelanggan, menu, dan karyawan. Proses transaksi penjualan yang ditunjang dengan adanya sistem informasi penjualan dan delivery order dapat dilakukan dengan lebih efektif, efisien, dan tepat waktu sehingga proses tersebut akan mempercepat waktu dan memperkecil kesalahan. 
Berdasarkan hasil dari simpulan, aplikasi ini telah berhasil dibangun sesuai kebutuhan yang ada pada Café Giova's Sentul, akan tetapi memerlukan pengembangan lebih lanjut agar dapat digunakan lebih baik. Untuk pengembangan selanjutnya diharapkan agar tampilan pada sistem ini dapat dibuat secara sempurna dan dapat dikembangkan agar lebih kompleks, dan perlu dibuatkan juga file backup data. Hal ini diperlukan untuk mengantisipasi jika terjadi kerusakan dan kehilang data, atau sesuatu yang tidak diinginkan terjadi pada data sehingga file backup sebelumnya dapat digunakan kembali.

\section{DAFTAR PUSTAKA}

Abdurahman, H. dan A. R. R. (2014). Aplikasi Pembayaran Secara Kredit Pada Bank Yudha Bahakti, Jurnal Computech \& Bisnis. Jurnal Computech \& Bisnis, 6169.

Ginting, E. (2013). Aplikasi Penjualan Berbasis Web (E-Commerce) Menggunakan Joomla Pada Mutiara Fashion. Universitas Udayana.

Haryanto. (2011). Esensi-esensi Bahasa Pemrograman Java. Penerbit Andi.

Isnandi, \& Wardati, I. U. (2014). Sistem Informasi Penjualan Tiket Pada Al Fath Tours Dan Travel Pacitan. Speed Journal - Sentra Penelitian Engineering Dan Edukasi.

Leon A. Abdillah., dkk. (2021). proses bisnis pengadaan. Yayasan Kita Menulis.

Rosa, A.S. dan Shalahudin, M. (2014). Rekayasa Perangkat Lunak Struktur dan Berorientasi Objek. Informatika.

Santoso, S. (2012). Panduan Lengkap SPSS Versi 20. PT Elex Media Komputindo.

Sutabri. (2012a). Analisis Sistem Informasi. Andi.

Sutabri, T. (2012b). Konsep Sistem Informasi. Penerbit Andi.

Westwood, J. (2011). How to Write a Marketing Plan. London: John Westwood Publishing. John Westwood Publishing. 